\title{
Development of a prognostic signature for esophageal cancer based on nine immune related genes
}

\author{
Zhi Zhang ${ }^{\dagger}$, Cheng Chen ${ }^{\dagger}$, Ying Fang, Sheng Li, Xiaohua Wang, Lei Sun, Guoren Zhou ${ }^{*}$ and Jinjun Ye
}

\begin{abstract}
Background: Function of the immune system is correlated with the prognosis of the tumor. The effect of immune microenvironment on esophageal cancer (EC) development has not been fully investigated.

Methods: This study aimed to explore a prognostic model based on immune-related genes (IRGs) for EC. We obtained the RNA-seq dataset and clinical information of EC from the Cancer Genome Atlas (TCGA).

Results: We identified 247 upregulated IRGs and 56 downregulated IRGs. Pathway analysis revealed that the most differentially expressed IRGs were enriched in Cytokine-cytokine receptor interaction. We further screened 13 survival-related IRGs and constructed regulatory networks involving related transcription factors (TFs). Finally, a prognostic model was constructed with 9 IRGs (HSPA6, S100A12, CACYBP, NOS2, DKK1, OSM, STC2, NGPTL3 and NR2F2) by multivariate Cox regression analysis. The patients were classified into two subgroups with different outcomes. When adjusted with clinical factors, this model was verified as an independent predictor, which performed accurately in prognostic prediction. Next, M0 and M2 macrophages and activated mast cells were significantly enriched in high-risk group, while CD8 T cells and regulatory T cells (Tregs) were significantly enriched in low-risk group.
\end{abstract}

Conclusions: Prognosis related IRGs were identified and a prognostic signature for esophageal cancer based on nine IRGs was developed.

Keywords: Esophageal cancer, Prognostic index, Immune-related genes, TCGA

\section{Background}

Esophageal cancer (EC) is the eighth commonest cancer worldwide. The National Cancer Institute estimated 16, 910 new cases and 15,910 deaths from esophageal cancer in the United States in 2016 [1]. Its incidence has risen by more than six times (1999-2008) [2]. The overall five-year survival of EC and that after esophagectomy are still poor, although great improvements have been made in treatment [3]. Squamous cell carcinoma is the

\footnotetext{
*Correspondence: zhouguoren888@126.com; jjye2004@163.com

${ }^{\dagger}$ Zhi Zhang and Cheng Chen contributed equally to this work.

Jiangsu Cancer Hospital \& Jiangsu Institute of Cancer Research \& Nanjing Medical University Affiliated Cancer Hospital, 42 Bai Zi Ting Road, Nanjing 210000, Jiangsu, China
}

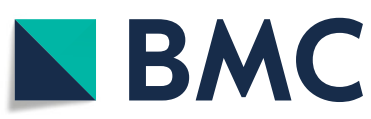

(C) The Author(s). 2021 Open Access This article is licensed under a Creative Commons Attribution 4.0 International License, which permits use, sharing, adaptation, distribution and reproduction in any medium or format, as long as you give appropriate credit to the original author(s) and the source, provide a link to the Creative Commons licence, and indicate if changes were made. The images or other third party material in this article are included in the article's Creative Commons licence, unless indicated otherwise in a credit line to the material. If material is not included in the article's Creative Commons licence and your intended use is not permitted by statutory regulation or exceeds the permitted use, you will need to obtain permission directly from the copyright holder. To view a copy of this licence, visit http://creativecommons.org/licenses/by/4.0/. The Creative Commons Public Domain Dedication waiver (http://creativecommons.org/publicdomain/zero/1.0/) applies to the data made available in this article, unless otherwise stated in a credit line to the data. most common histological type of EC [4]. Tobacco, alcohol, and malnutrition are the most associated risk factors in the development of EC [5]. Once diagnosed, EC must be accurately staged prior to the initiation of treatment. TNM (tumor, lymph node, metastasis) is a staging system based on the status of tumor invasion, lymph node, and metastasis [6]. Early-stage EC is usually treated with endoscopic surgery, advanced EC with surgery with or without chemoradiation [7].

Certain specific genes and biomarkers are needed to predict the patient's therapeutic response and increase their survival [3]. Immune responses is critical in the tumor microenvironment. Tumor cells with genomic 
alterations can produce new antigens that can be recognized by the immune cells [8]. Expression of IRGs can serve as efficient biomarkers. Previous research have explored the IRGs-based prognostic features in patients with non-squamous non-small cell lung cancer [9] and papillary thyroid carcinoma [10]. However, prognostic models based on IRGs for EC remain to be elucidated.

This study investigated the clinical significance of a prognostic model based on immunogenomics.

\section{Materials and methods \\ Data collection}

The mRNA profiles and corresponding clinical information of 11 normal tissues and 160 EC samples were downloaded from TCGA (https://www.cancer.gov/) [11], which including 81 Esophagus Squamous Cell Carcinoma (ESCC) and 79 Esophagus Adenocarcinoma (EA). A set of IRGs were obtained through the Immunology Database and Analysis Portal (ImmPort) database (https://www.immport.org) [12]. A set of tumor-related TFs were obtained from Cistrome Cancer (http://cistrome.org/CistromeCancer/) [13]. CIBERSORT (https://cibersort.stanford.edu/index.php) is based on a gene expression deconvolution algorithm [14] for obtaining immune cells with differences between cancer and normal tissues.

\section{Identification of differentially expressed genes (DEGs)}

DEGs between EC and normal tissues were identified via $\mathrm{R}$ software (version: $\times 64.3 .2 .1$ ) and package Limma. The $p$ value was adjusted into the false discovery rate (FDR). A value of FDR less than 0.05 and $|\log 2(\mathrm{FC})|$ higher than 1 were considered significant.

\section{Identification of immune-related genes (IRGs)}

DEGs overlapped with immune-related genes were obtained as the differentially expressed IRGs. Based on these IRGs, Gene Ontology (GO) [15] and Kyoto Encyclopedia of Genes and Genomes (KEGG) [16] analyses were performed with the clusterprofiler R package to explore the underlying mechanisms of these IRGs.

\section{Identification of prognosis-related IRGs and construction of regulatory network}

Prognosis-related IRGs were identified using univariate COX regression analysis. We analyzed these prognosisrelated IRGs using the package $\mathrm{R}$. Then, we investigated the interaction of these IRGs and differentially expressed TFs with a threshold of $P<0.05$. Coefficient $>0.3$ was considered as positive regulation, otherwise as negative regulation. Subsequently, we constructed a regulatory network with relevant TFs and prognosis-related IRGs by using cytoscape software 3.7.1 [17].
Construction of a prognostic model in EC based on IRGs We constructed a prognostic model based on the results of a multivariate Cox regression analysis. Based on the median risk score, EC patients were divided into highrisk and low-risk groups. The performance of prognostic model was validated by survival analysis between groups with thresholds of $p<0.05$ using the survival and survminer package of $\mathrm{R}$. Receiver operating characteristic (ROC) analysis was performed via the survivalROC package, and the area under curve (AUC) was calculated to evaluate the efficiency of the model in predicting disease onset [18]. At the same time, we collated the patient's clinical information and deleted the incomplete information. Finally, a total of 115 patients' clinical information (Supplementary Table 1) were used for univariate and multiple regression analysis to determine whether the riskscore may become an independent predictor of ESCC. Association between IRG expression and clinical parameters was tested using independent $\mathrm{t}$ tests, and $p<0.05$ were considered statistically significant. Clinical survival analysis in subgroups was also conducted, and $\mathrm{p}<0.05$ was considered statistically significant.

\section{Verification of the prognosis-related IRGs in this model} We used the online software Oncomine (https://www. oncomine.org) to verify the IRGs. For screening, we set the following criteria: 1 "Gene: IRGs in this model"; 2 "Analysis Type: Cancer vs. Normal Analysis"; 3 "Cancer Type: Esophageal Cancer”; 4“ Clinical Outcome: Survival Status "; 5 "Data Type: mRNA". Based on the specific binding between antibodies and antigens, immunohistochemistry can reveal the relative distribution and abundance of proteins. Using The Human Protein Atlas (THPA) (https://www.proteinatlas.org) [19], we observed the differences in key gene expression between normal and EC tissues.

\section{Building a predictive nomogram}

To investigate the possibility of EC 1-OS and 3-OS, we established nomograms by including all independent prognostic factors identified by multivariate Cox regression analysis. The effectiveness of the nomogram was evaluated by discrimination and calibration. Finally, we plotted the curve of the nomogram by package rms of $R$ to observe the relationship between the predicted rate of nomogram and the observed rate.

\section{Functional enrichment analysis}

We used Gene Set Enrichment Analysis (GSEA) [20] to identify consistent differences between high-risk and low-risk groups and the associated biological processes. In screening the gene list of KEGG, $p<0.05$ was considered statistically significant. 
Differential expression of tumor-infiltrating immune cells between high-risk and low-risk groups

Status of immune infiltration in EC patients was achieved from the dataset of CIBERSORT. Subsequently, we tested the abundance of immune cells, and its difference between high-risk and low-risk groups by using two-sample T-test.

\section{Results}

\section{DEGs between EC and normal samples}

The RNAseq tertiary data set of EC from TCGA included the biological information of 11 normal tissue and 160 EC samples. We identified 4094 DEGs, including 3272 upregulated DEGs and 822 downregulated DEGs. (Fig. 1a).

\section{Identification of IRGs}

By overlapping the immune-related genes and DEGs of EC, we identified 247 upregulated and 56 downregulated IRGs, as shown in Fig. 1b. Figure 2 shows the results of functional enrichment analysis. GO analysis (Fig. 2a) demonstrated that these IRGs were most involved in leukocyte migration in Biological Process (BP), vesicle lumen in Cellular Component (CC) and receptor ligand activity in Molecular Function (MF). KEGG analysis indicated that these genes were most involved in the interaction of cytokines with cytokine receptors. (Fig. 2b).

Survival analysis and construction of regulatory network A total of 13 survival-associated IRGs were identified after integrating clinical information from TCGA via univariate COX regression, as shown in Fig. 3. After examining the expression of 318 transcription factors (TF), we found 61 with differential expressions between EC and normal samples, as shown in Fig. 4a, b. Finally a regulatory network was constructed using these survivalassociated IRGs with differently expressed TFs (Fig. 4c).

\section{Construction of a prognostic model based on prognosis-} related IRGs and external validation

We constructed a prognostic model with nine prognostic IRGs based on the results of multivariate Cox regression analysis (Table 1). The formula was as follows: Risk score $=$ expression level of HSPA6*0.006713979+ S100A $12 * 0.003828117+$ CACYBP*0.042341765 + NOS2*0.02490294 + DKK1*0.015602891 + OSM*0.207589957 + STC2*0.075574581 + ANGP TL3*0.645334283 + NR2F2*0.015710952. We further explored the protein expression of these nine prognosisrelated IRGs in THPA (Fig. 5). Consistent with our results, THPA database showed that HSPA6, S100A12, CACYBP, NOS2, and STC2 in EC tissues were upregulated, and ANGPTL3 was down-regulated compared with those in normal tissues. However, we did not find expression of DKK1, OSM and NR2F2 proteins in the database.

Validation of the prognosis-related IRGs in the Oncomine database

We validated the reliability of the prognosis-related IRGs by using Oncomine. The databases showed that the IRGs were differentially expressed in EC and normal
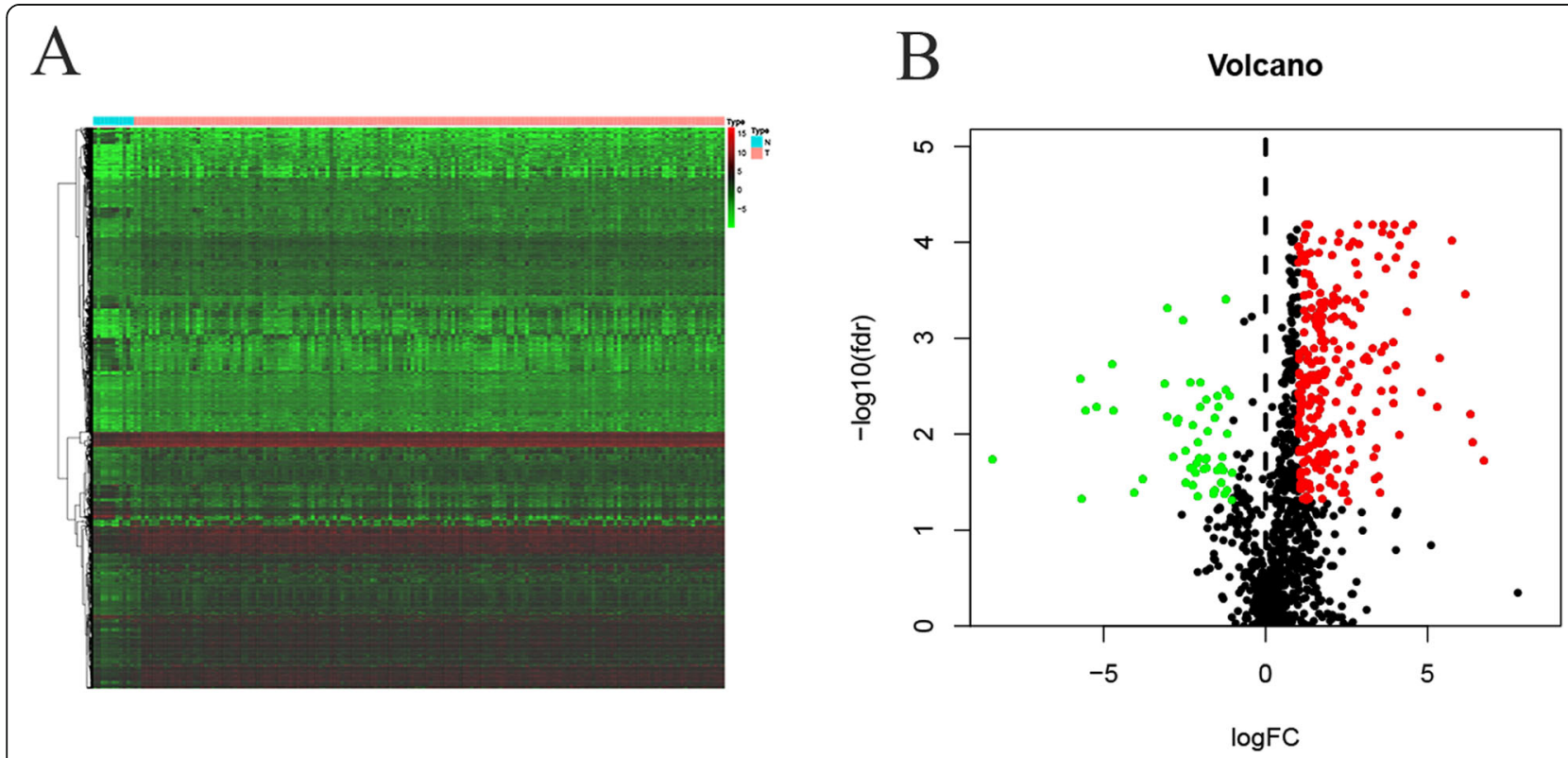

Fig. 1 Differential expression analysis of DEGs and IRGs. a Heatmap of DEGs; Red plots: upregulation; Green plots: downregulation; Black plots: normally expressed mRNAs. b Volcano plot of IRGs; Red, green and black plots: differentially expressed mRNAs as indicated in A 


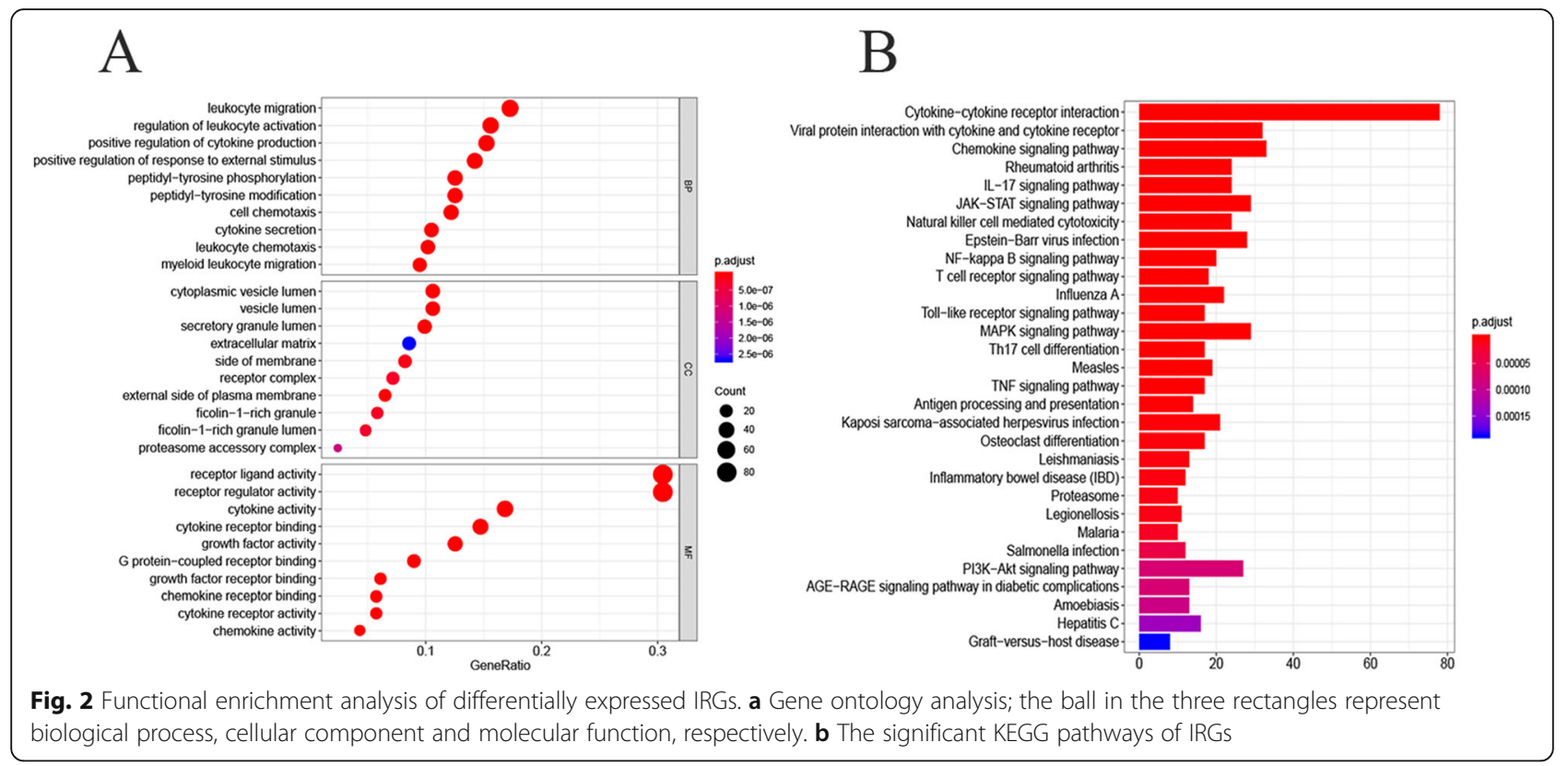

tissues. As shown in Supplementary Fig. 1, HSPA6, S100A12, CACYBP, NOS2, DKK1, OSM and STC2 were up-regulated, and ANGPTL3 and NR2F2 were downregulated in EC tissues compared with those in normal tissues. We found that the results were almost consistent with our predictions.
Validation of the prognostic capacity of the model

Patients were separated into the high-risk group and the low-risk group based on the median risk score (Fig. 6 ac). Survival analysis showed that the survival rate in the high-risk group was remarkably lower than those in the low-risk group ( $p==2.366 \mathrm{e}-06$, Fig. $6 \mathrm{~d}$ ). The area under

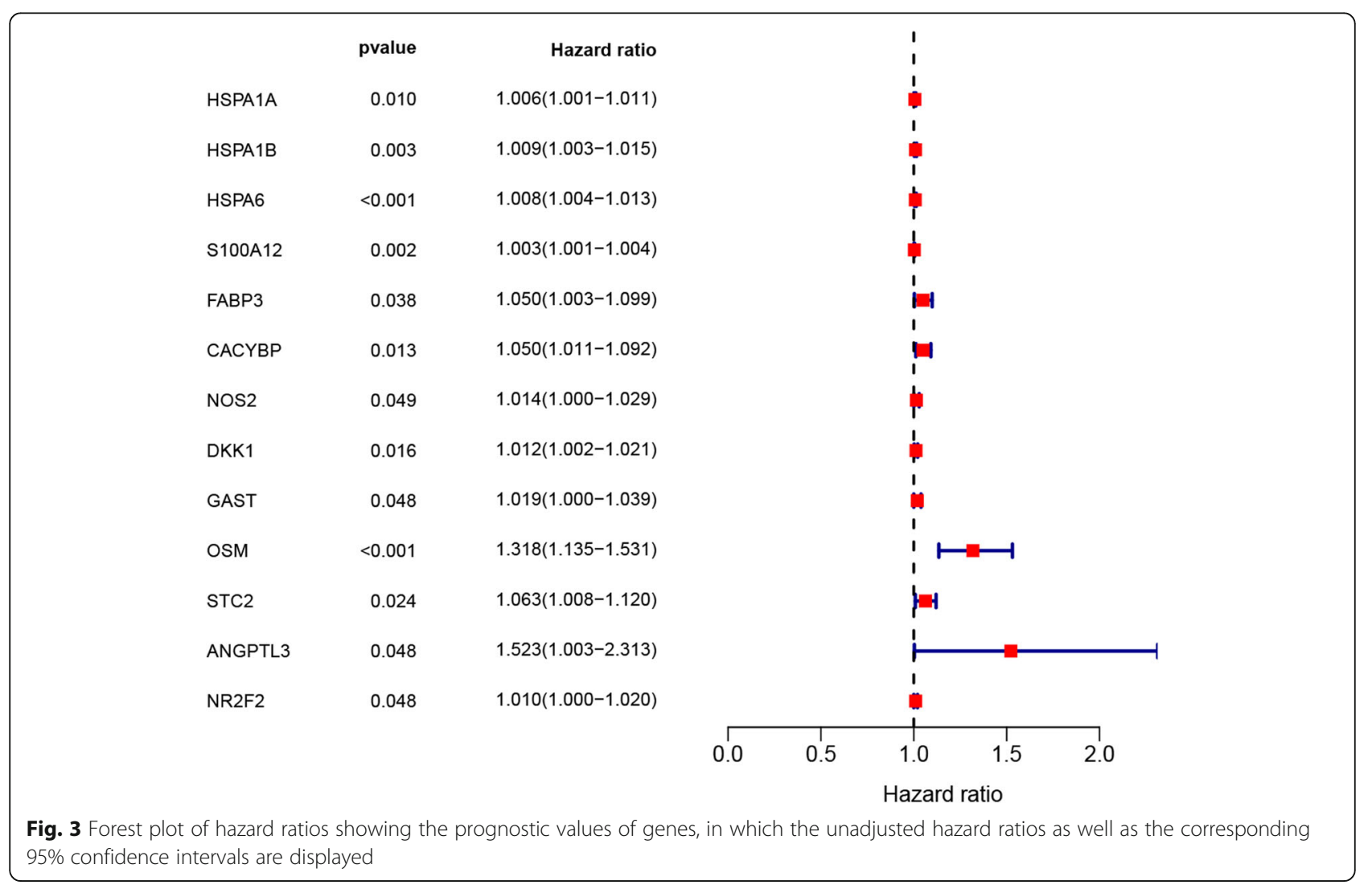



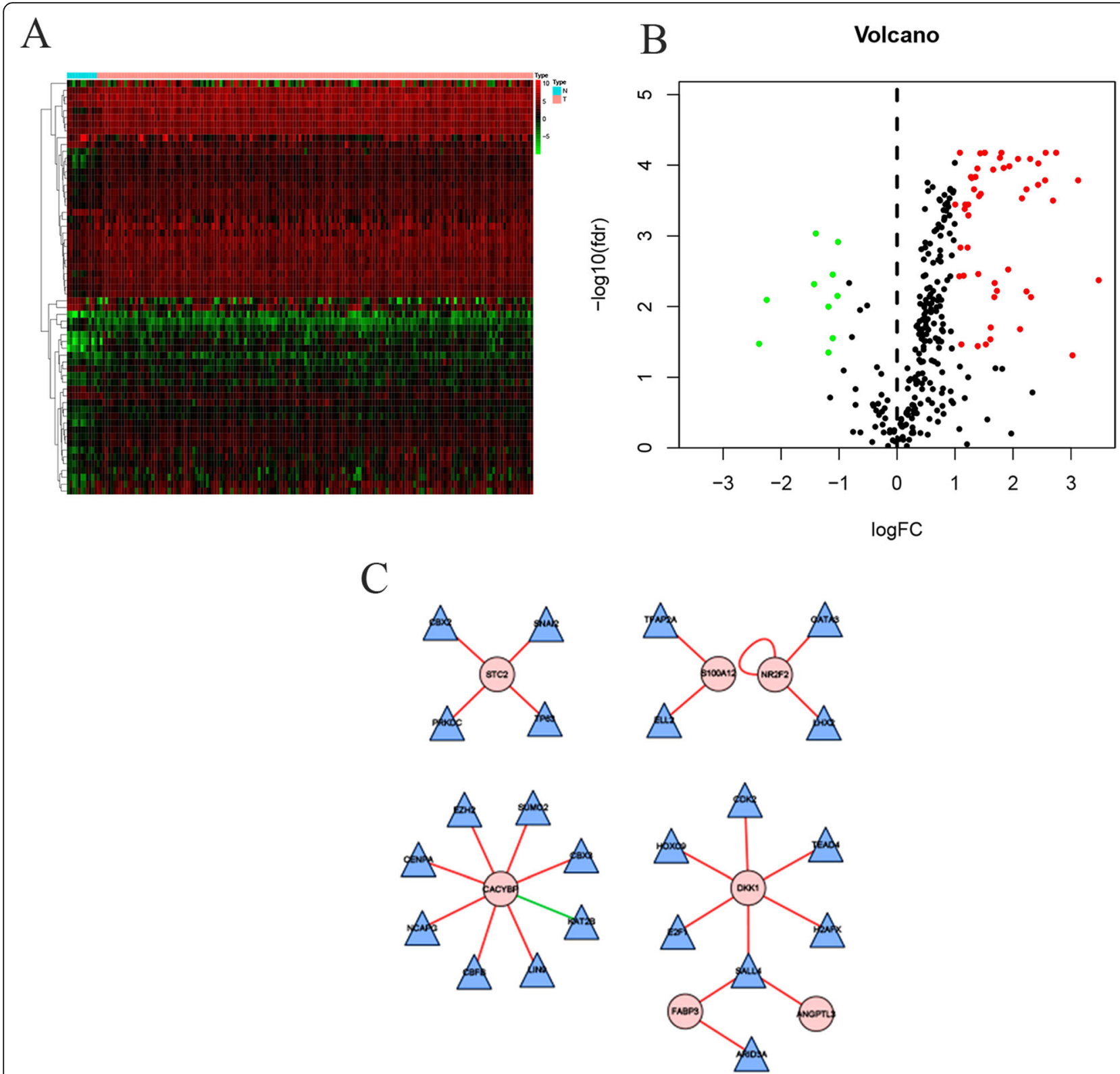

Fig. 4 Differential expression analysis of TFs and the regulatory network. a Heatmap of TFs, red: upregulation; green: downregulation; black: normally expressed mRNAs. $\mathbf{b}$ Volcanic maps of TFs; red, green and black plots: differentially expressed mRNAs as indicated in A. c Regulatory network integrated the survival associated IRGs and differentially expressed TFs; the circles filled with pink represent the survival associated IRGs and the triangles filled with blue represent TFs

curve (AUC) of the receiver operating characteristic (ROC) curve was 0.826 (Fig. 6e). Compared with clinical factors (including age, gender, grade, stage and TMN), this signature showed a greater performance in predicting the prognosis of EC. At the same time, univariate and multiple regression analysis (Fig. 7a, b) showed that when other clinical parameters were adjusted, the prognostic signature may become an independent predictor. The clinical significance of included genes was also explored in this study (Fig. 8a-j). In order to assess the prognostic capacity of the model, we conducted a stratified analysis of clinical factors. Interestingly, we found that nearly the high-risk patients in subgroups of age $\leq 65$ (Fig. 9a), male (Fig. 9b), G1 \& G2(Fig. 9c), stage III \& IV (Fig. 9d), T-3-4(Fig. 9e), MO (Fig. 9f), N1-3(Fig. 9g) and EAC (Fig. 9h) were inclined to unfavorable overall survival.

\section{Construction and validation of predictive nomogram}

Using a number of independent prognostic factors (including age, gender, grade, stage, TMN, histology, and 
Table 1 The immune-based prognostic index model of EC

\begin{tabular}{llllll}
\hline id & coef & HR & HR.95 L & HR.95H & pvalue \\
\hline HSPA6 & 0.006713979 & 1.006736568 & 1.000468103 & 1.013044308 & 0.035133319 \\
S100A12 & 0.003828117 & 1.003835454 & 1.002153991 & 1.005519738 & $7.62 \mathrm{E}-06$ \\
CACYBP & 0.042341765 & 1.043250965 & 0.992392076 & 1.09671631 & 0.096819638 \\
NOS2 & 0.024902941 & 1.02521561 & 1.009716012 & 1.040953134 & 0.001355421 \\
DKK1 & 0.015602891 & 1.015725251 & 1.005677036 & 1.025873864 & 0.002098124 \\
OSM & 0.207589957 & 1.230708423 & 1.044607882 & 1.449963424 & 0.013076143 \\
STC2 & 0.075574581 & 1.07850366 & 1.018550661 & 1.141985558 & 0.009601837 \\
ANGPTL3 & 0.645334283 & 1.906624275 & 1.249904495 & 2.908395112 & 0.002741427 \\
NR2F2 & 0.015710952 & 1.015835018 & 1.0055558018 & 1.026217051 & 0.002459204 \\
\hline
\end{tabular}

risk scores), we established a nomogram to predict 1year and 3-year OS in 100 EC patients. The calibration chart showed that the nomogram might overestimate or underestimate the mortality (Fig. 10). These results suggested that the nomogram based on multiple factors can better predict short-term survival (1 year and 3 years) compared to the nomogram based on a single factor.

\section{Identification of related biological processes and pathways}

We employed risk score to classify the entire data set and determine the related pathways with these nine genes by using the Java software GSEA. The results showed that "one carbon pool by folate", "proteasome", "spliceosome" and "RNA degradation" were more abundant in the high-risk group than in the low-risk group. This suggests that in high-risk patients, the nine genes were most involved in pathways of protein degradation, RNA degradation and splicing. That is to say, patients with protein degradation, RNA degradation and splicing effects were more inclined to a poor prognosis (Fig. 11).

\section{Difference of tumor-infiltrating immune cells between the two risk groups}

To explore the relationship between the present IRGbased prognostic signature and tumor immune microenvironment, we compared the infiltration of immune cells in different risk groups as defined by the present IRG-based prognostic signature. The results showed that Macrophages M0, Macrophages M2 and activated mast cells were significantly enriched in high-risk group, while CD8 $\mathrm{T}$ cells and regulatory $\mathrm{T}$ cells (Tregs) were significantly enriched in the low-risk group (Fig. 12). At the same time, there was no significant difference in the enrichment of some other immune subsets between the two groups, such as B cells naive, Eosinophils, Mast cells resting, $\mathrm{T}$ cells gamma delta, $\mathrm{T}$ cells follicular helper, Plasma cells, NK cells resting, Macrophages M1, B cells memory, Monocytes, T cells CD4 memory resting, Dendritic cells resting, Neutrophils, Dendritic cells activated,
T cells CD4 memory activated and NK cells activated (Supplementary Fig. 2).

\section{Discussion}

Esophageal cancer has a large number of new cases every year, and it has historically been regarded as an uncontrollable disease process. The etiology of esophageal cancer may be multifactorial, but part of it is due to the unique manifestation of this cancer [21]. At present, for the treatment of esophageal cancer, attention has shifted to the development of immunotherapy with novel immune biomarkers [22]. Somatic cells acquire malignancy through genetic alterations. Cancer cells usually evade the recognition of the immune system and develop into clinically meaningful masses [23]. Compared with conventional therapies, cancer immunotherapy shows long-lasting response with fewer adverse reactions [24]. This provides a new option for the treatment of EC.

The prognostic model for EC has been continuously updated [25-27]. In this study, we identified 247 upregulated and 56 down-regulated IRGs in EC and screened out survival-related IRGs. Based on these data, we established a prognostic model that divided EC patients into high-risk and low-risk groups. This model showed a good predictive performance (AUC 0.826). The model was also an independent prognostic indicator by multivariate analysis incorporating other clinical factors. KEGG analysis indicated that the main pathway was enriched in cytokine-cytokine receptor interaction. Many biological processes are regulated by cytokines, including cell growth, differentiation, immunity, inflammation, and metabolism [28]. Tumor progression can be promoted by cytokines that affect the tumor microenvironment and directly act on cancer cells [29]. Moreover, cytokines participate in the immune response of cytotoxic T lymphocytes (CTLs) by modulating the differentiation of Th1 and Th2 cells [30]. Kita Y et al. found that STC2 may be involved in lymph node metastasis, making it a potential prognostic marker for patients with EC 
Tumor

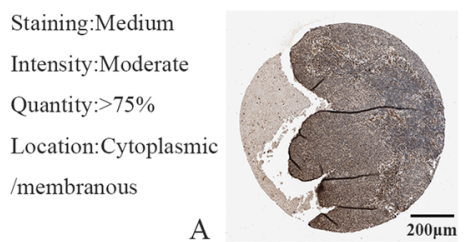

A

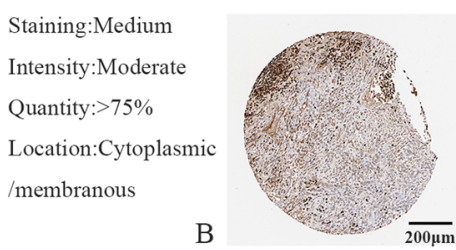

Staining:High Intensity:Strong Quantity: $>75 \%$ Location:Cytoplasmic /membranous

C

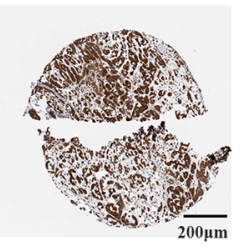

Staining:Not detected Intensity:Negative Quantity:None Location:None
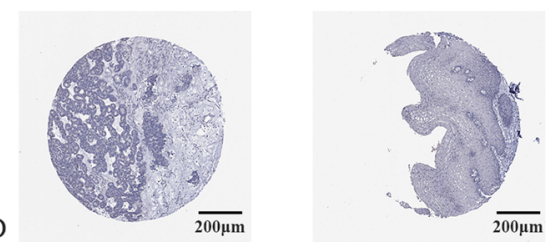

Staining:Not Intensity:Negative Quantity:None Location:None
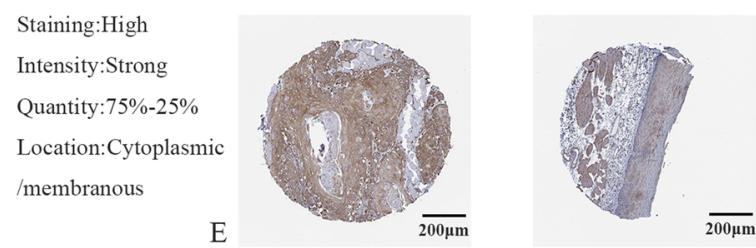

StainingMedium Intensity:Moderate Quantity:75\%-25\% Location:Cytoplasmic membranous

Staining:Notdetected Intensity:Negative Quantity:None Location:None

Staining:High Intensity:Strong Quantity: $>75 \%$ Location:Cytoplasmic /membranous

Staining:Notdetected Intensity:Weak

Quantity: $<25 \%$

Location:Cytoplasmic /membranous
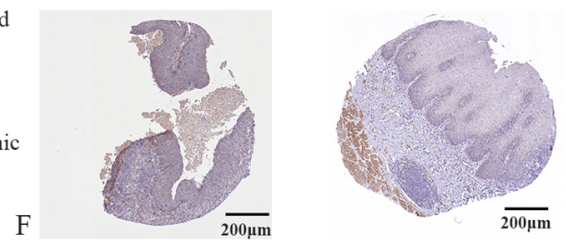

Staining:Not detected Intensity:Negative Quantity:None Location:None

Fig. 5 Protein expression of genes in the model. a protein expression of HSPA6. $\mathbf{b}$ protein expression of S100A12. c protein expression of CACYBP. $\mathbf{d}$ protein expression of NOS2. e protein expression of STC2. $\mathbf{f}$ protein expression of ANGPTL3

[31]. Studies also demonstrated that STC2 may play an important role in ESCC tumorigenesis [32]. Abnormal expression of DKK1, which is regulated by DKK1CKAP4 pathway, predicts the poor prognosis of esophageal squamous cell carcinoma (ESCC) [33]. These results are consistent with our findings. CacyBP regulates cell proliferation, tumorigenesis, differentiation or gene expression [34]. In colon cancer, CacyBP can promote the growth of cancer cells by enhancing the ubiquitinmediated degradation of p27kip1 [35]. In addition, 
$\mathrm{D}$
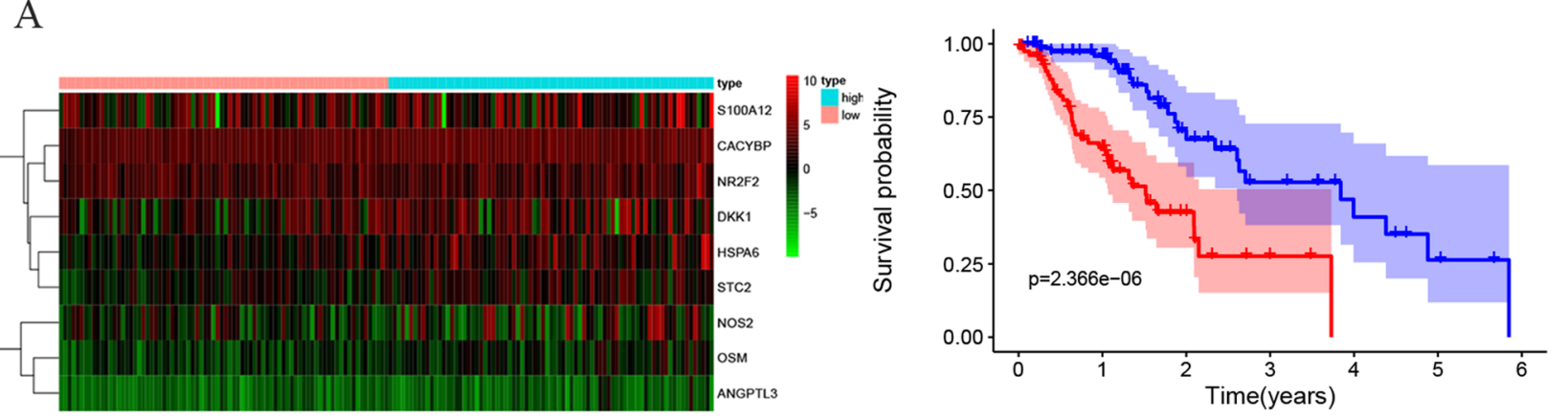

$\mathrm{B}$
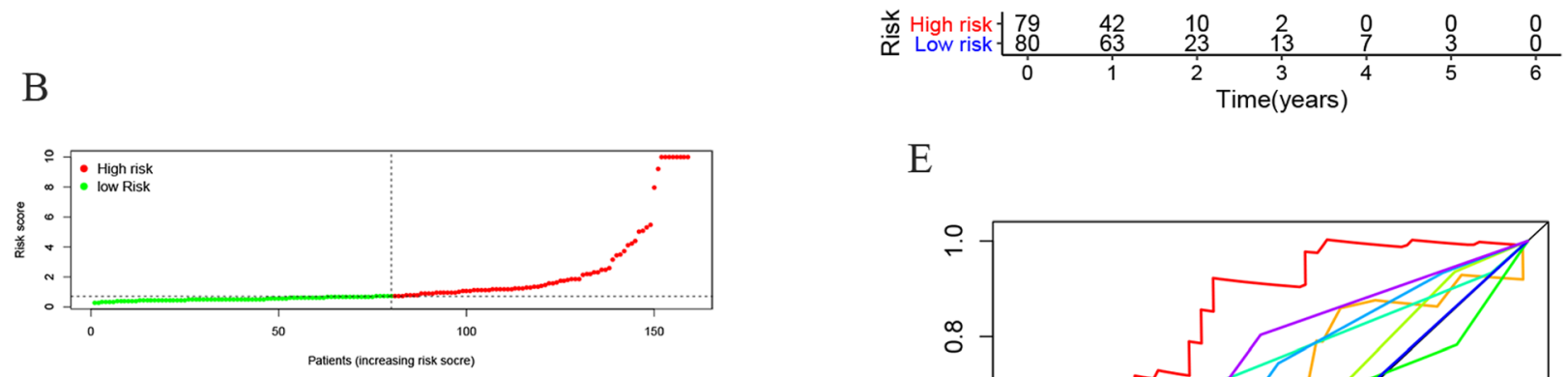

E
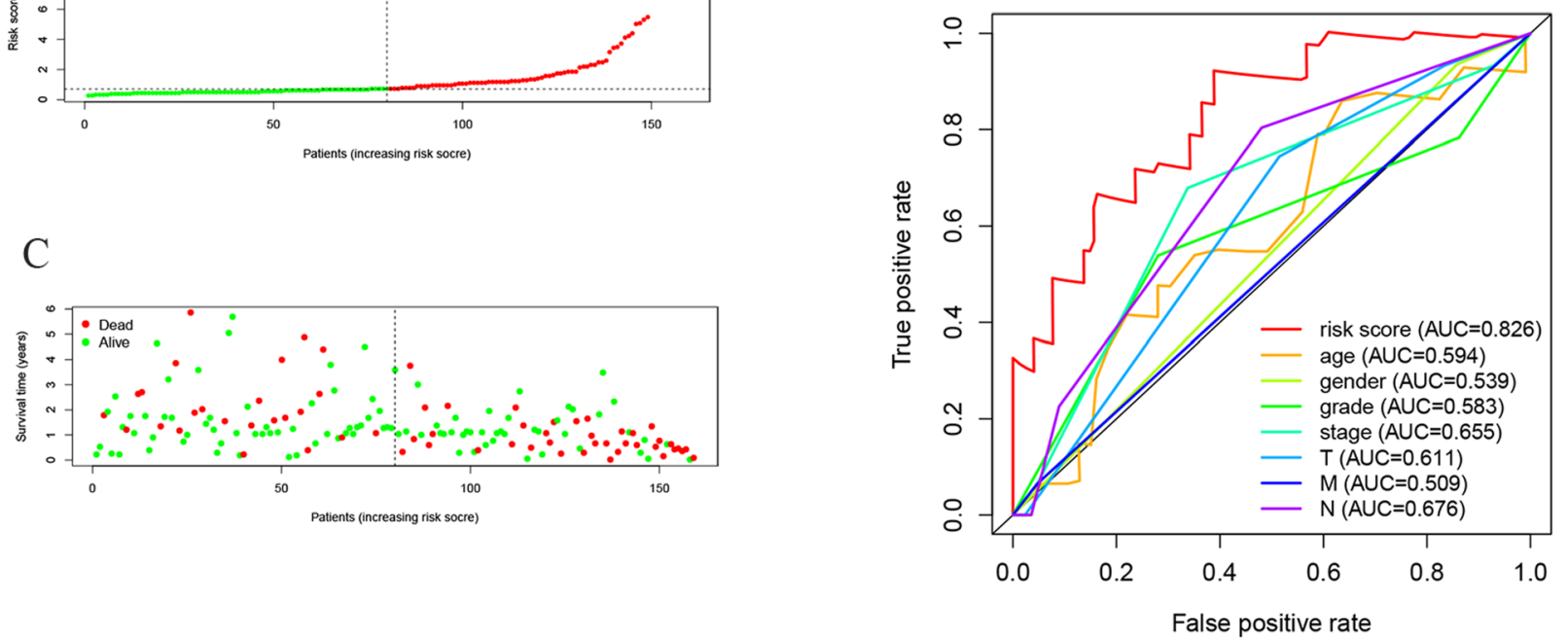

Fig. 6 The prognostic value of prognostic index developed based on IRGs. a Heatmap of expression profiles of included IRGs. b Survival status of patients in different groups. c Rank of prognostic index and distribution of groups. d Survival analysis between the two groups.e ROC curve of the prognostic index model
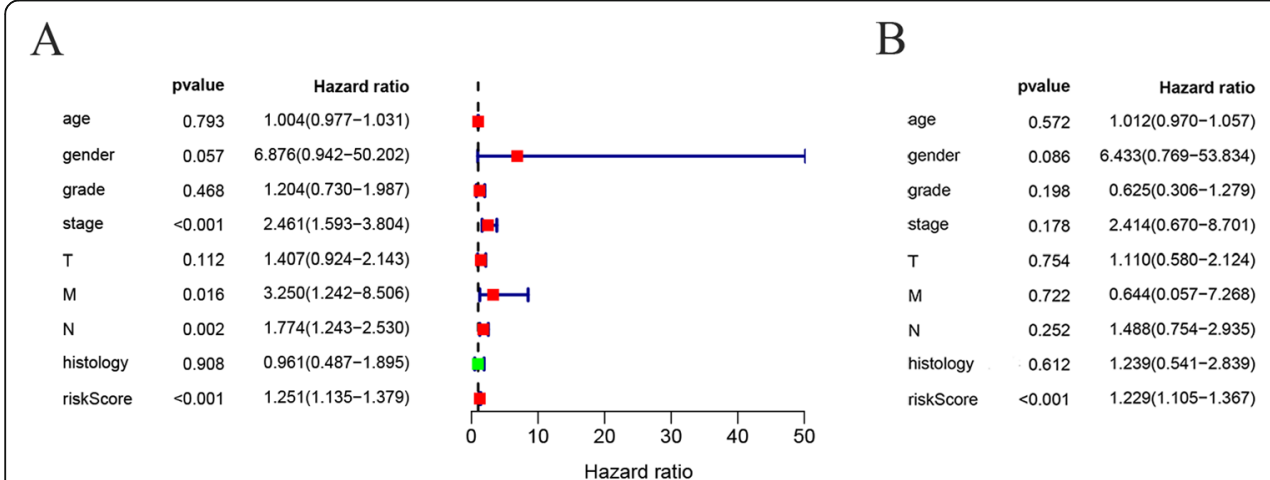

Fig. 7 Forest plots including the risk score and other clinical parameters by univariate (a) and multiple regression analysis (b), in which the unadjusted hazard ratios as well as the corresponding $95 \%$ confidence intervals are displayed 


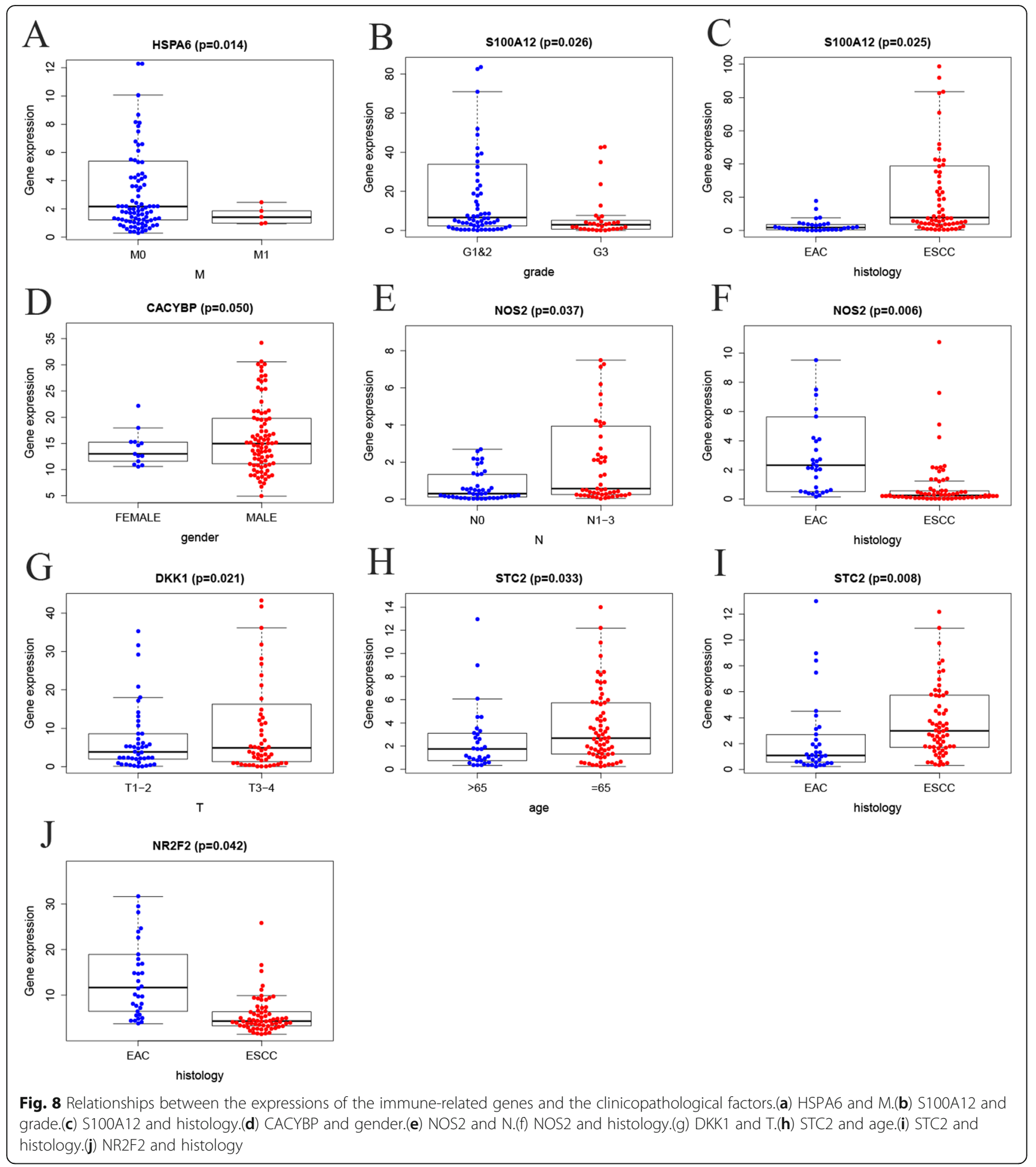

studies have confirmed that CacyBP level increased in gastric, nasopharyngeal carcinoma, osteogenic sarcoma and melanoma [36, 37].

In our prognostic model, the IRGs showing prognostic values included HSPA6, S100A12, CACYBP, NOS2, DKK1, OSM, STC2, ANGPTL3 and NR2F2. Among the, HSPA6 may be associated with early recurrence of HCC
[38]. In ESCC, S100A12 is downregulated at the protein level [39]. In Barrett's esophagus and related adenocarcinoma, expression of inducible nitric oxide synthase (NOS-2) is increased, and NOS-2 also plays a role in inflammation and epithelial cell growth [40]. OSM has been identified as an inhibitor of tumor cell growth in a variety of cancers, including melanoma, ovarian cancer, 


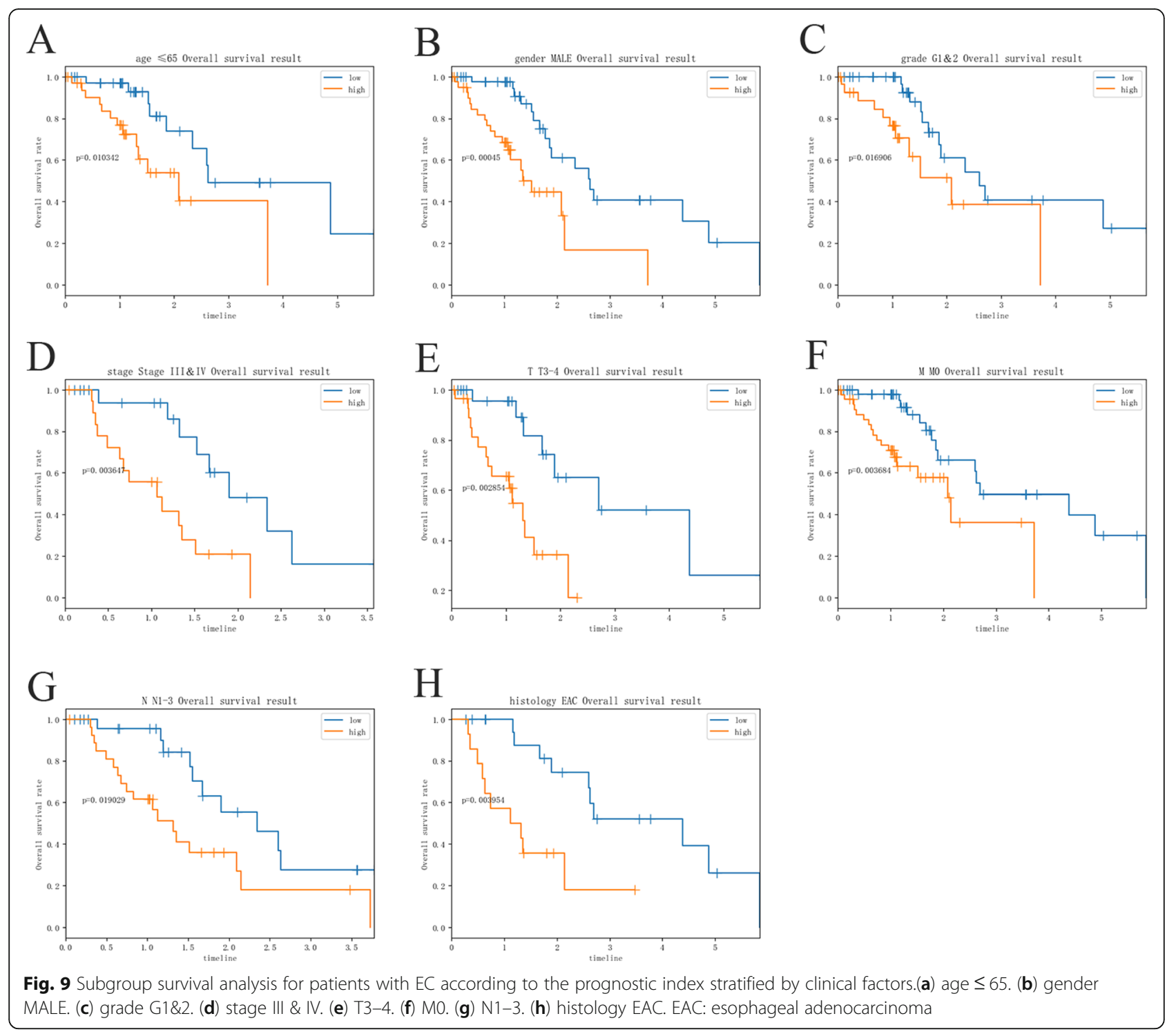

and glioblastoma carcinomas [41-43]. The splice variant of oncostatin $M$ receptor $\beta$ is overexpressed in human esophageal squamous cell carcinoma [44]. Angiopoietinlike protein 3(ANGPTL3) is indicative of EC prognosis [45]. NR2F2 is involved in the progression of prostate adenocarcinoma [46], and NR2F2 expression is a prognostic factor for breast neoplasms [47]. High expression of NR2F2 in certain gastric and esophageal adenocarcinomas is associated with abnormal expression of cadherin 11, suggesting that the NR2F2-related embryonic pathways in these tumors are reactivated [48]. Proteasome dysregulation is implicated in the development of many types of cancer [49]. The proteasome is involved in cell cycle and transcription, two processes indispensable for cancer development [50]. The spliceosome catalyzes premRNA splicing, a key regulatory step in gene expression $[51,52]$. Mutations in genes encoding splice proteins are frequently found in cancer [53]. Small molecule inhibitors that target splice components can be used to create anti-cancer drugs [52]. RNA degradation is a key posttranscriptional regulatory checkpoint to maintain proper functions of organisms. Ribonuclease, a key enzyme responsible for RNA stability, can be used alone for RNA degradation, and can bind to other proteins in the RNA degradation complex [54].

Previous immunotherapies mainly rely on $\mathrm{T}$ cells in tumor immune defense $[55,56]$. In the present research, the abundance of $\mathrm{CD} 8 \mathrm{~T}$ cells and regulatory $\mathrm{T}$ cells in the low-risk group increased. T cells are critical in host defense against cancer [57]. The value of CD8 $\mathrm{T}$ cells for cancer prognosis has been assessed [58-62]. In addition, CD8 T cells also play a role in the progression of EC $[63,64]$.

Tregs are divided into two major subpopulations: thymus-derived Tregs (nTregs) and inducible Tregs 

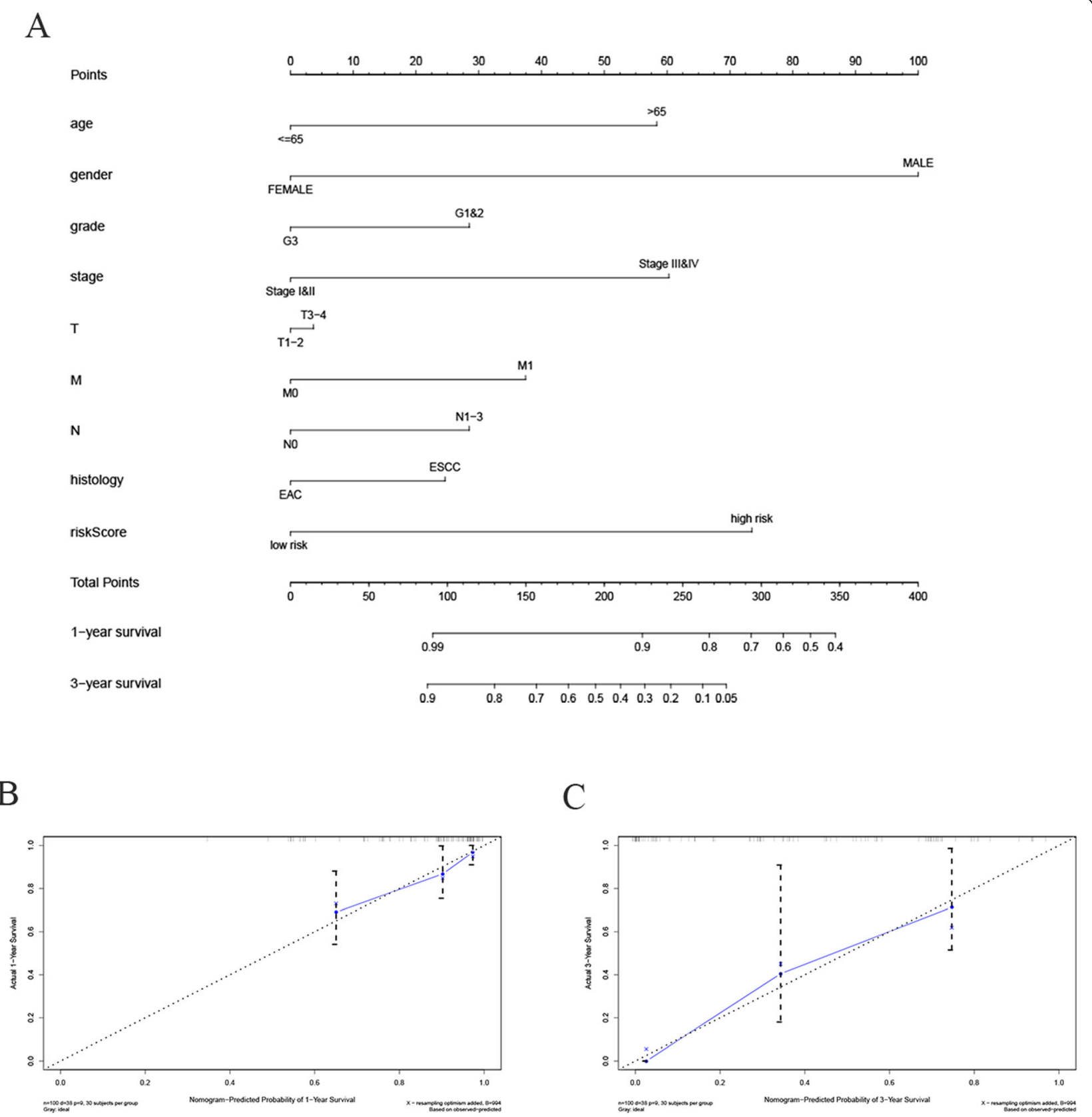

Fig. 10 Nomogram predicting overall survival for EC patients. a For each patient, several lines are drawn upward to determine the points received from the predictors in the nomogram. The sum of these points is on the "total point" axis. Then a line is drawn downward to determine the possibility of 1- and 3-year overall survival of EC. $\mathbf{b}, \mathbf{c}$ The calibration plot for internal validation of the nomogram. The Y-axis represents actual survival, and the $\mathrm{X}$-axis represents nomogram-predicted survival

(iTregs) [65]. Tregs show significant versatility in their inhibitory mechanisms by releasing cytokines to directly inhibit signal transduction of effector T cells [66]. Tregs can also inhibit and kill B cells by inducing programmed cell death [67]. Indeed, Treg infiltration into the tumor has been negatively correlated to OS in a majority of human solid tumors $[68,69]$. However, this correlation is highly variable, depending on the tumor type [70]. In cancers that share a common feature of prominent chronic inflammation, such as colon, breast, bladder or head and neck cancers, intra-tumor accumulations of Treg appear to associate with favorable prognosis and improved OS [71-73] .This association has been explained by the capability of Treg to suppress "tumor promoting inflammation" (TPI). Moreover, previous study found that regulatory $\mathrm{T}$ cells are positively 


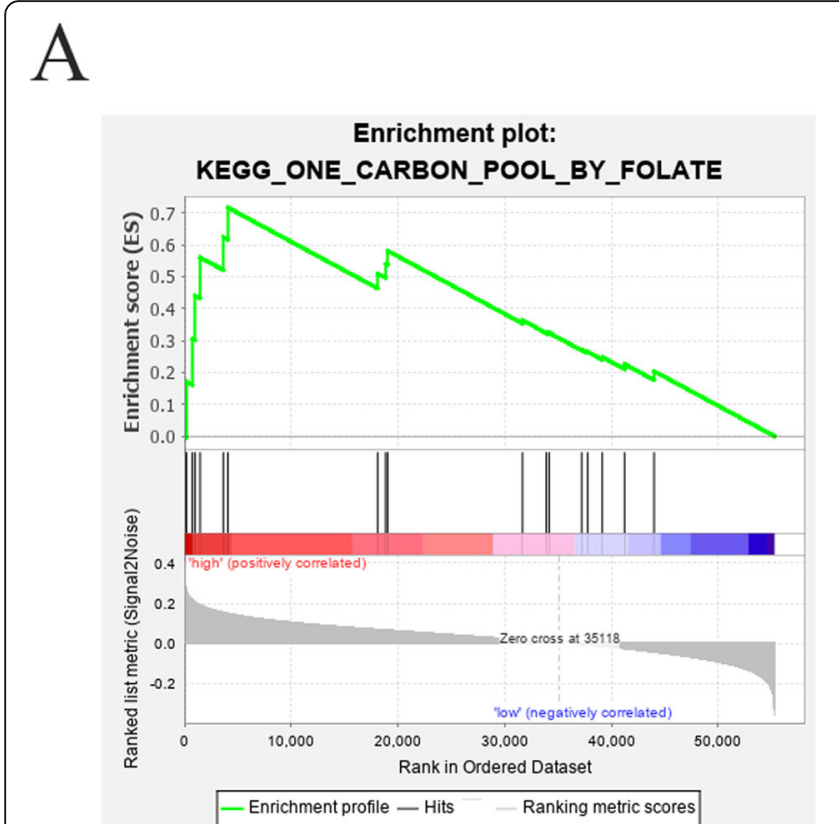

\section{B}

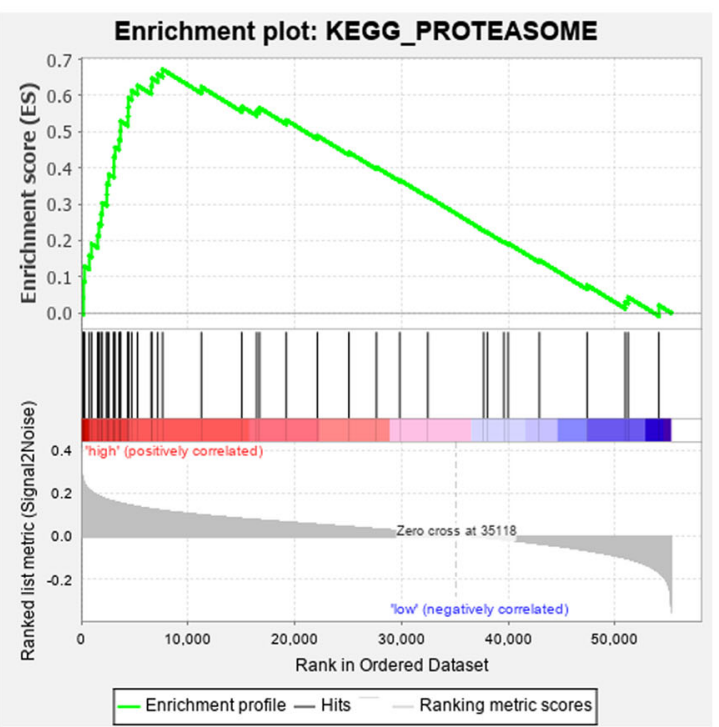

$\mathrm{C}$

$\mathrm{D}$
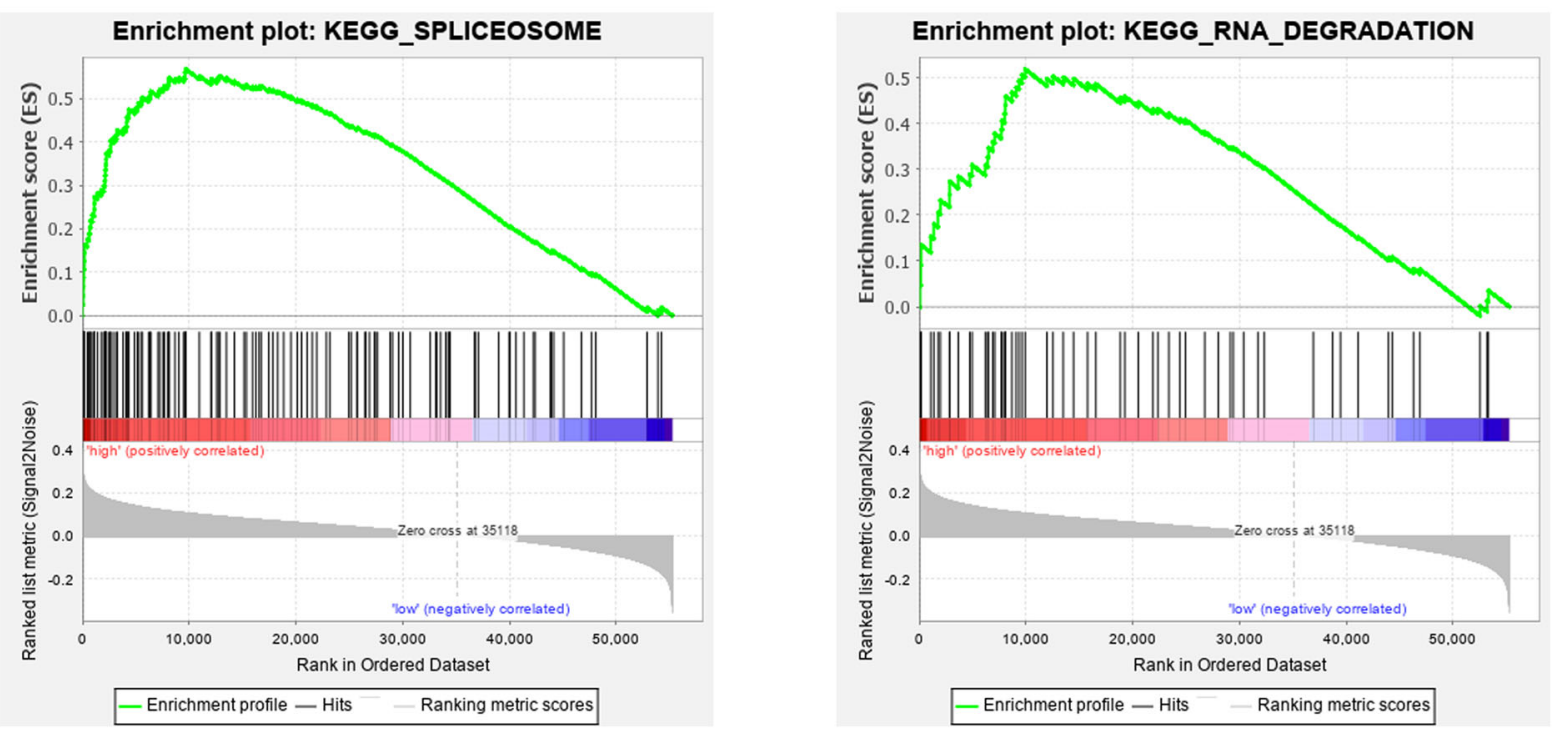

Fig. 11 GSEA results for high and low risk differentially expressed genes in TCGA for (a) one carbon pool by folate, (b) proteasome, (c) spliceosome, and (d) RNA degradation

correlated with locoregional control may be through down-regulation of harmful inflammatory reaction, which could favor tumor progression in head and neck squamous cell carcinoma [71]. So it can be explained that why the abundance of regulatory $\mathrm{T}$ cells (Treg) in the low-risk group was higher than in the high-risk group in our finding. In high-risk group, we found that macrophages M0, M2 and activated mast cells were also significantly enriched. Tumor-associated macrophages are the most abundant cancer immune cells. Studies have found that the transcription factor forkhead box protein O1 (FOXO1) can promote the polarization of macrophages M0 to M2 and the recruitment of macrophages M2 in ESCC through transcriptional regulation [74]. Macrophage M2 can be transformed into macrophage M1, and can promote the proliferation, migration and ring-forming ability of lymphatic endothelial cells associated with EC [75]. In addition, macrophage M2 can promote the migration and invasion of ESCC cells, enhance the epithelial-mesenchymal transition process, 


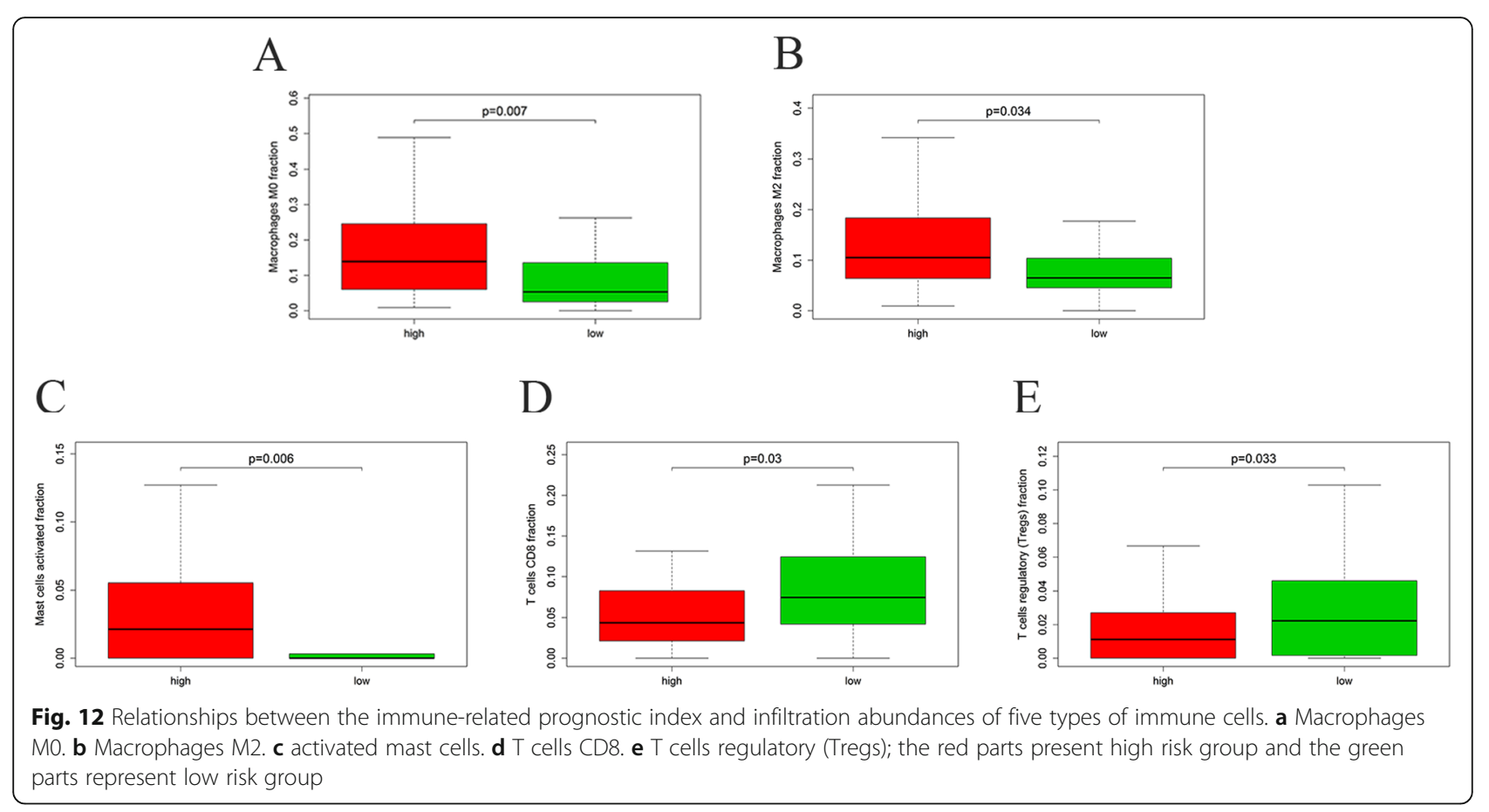

and promote tumor progression, resulting in poor prognosis for ESCC patients [76]. Tissue kallikrein (TK1), which is highly expressed in activated mast cells, can participate in the formation of mitogenic kinin, which can stimulate the proliferation of tumor cells and enhance metastasis by increasing vascular permeability [77]. All these researches above can support the finding of our study.

It is the first time that a prognostic nomogram is developed with nine immune related genes. This nomogram can be routinely applied and is cost-effective in practice, as it does not need whole-genome sequencing for EC patients. When combined with clinical parameters like TNM stage, the nomogram can show a greater prognostic performance.

Although we constructed a novel nine-gene prognostic signature in esophageal cancer, several limitations of this study should also be acknowledged. Firstly, our prognostic signature was only based on the data from TCGA database, which is not validated in other databases or other centers across different populations. The performance of this prognostic signature might be more reliable if validation is performed with independent external data sets with long-term follow up. Secondly, this study only preliminary proposed a prognostic model and the validity of the five-gene signature model needs to be further verified by clinical trials. Our study was designed on the basis of a retrospective analysis and prospective research should be performed to verify the outcomes. Thirdly, the mechanisms underlying the nine immune-related genes in the prognosis prediction of esophageal cancer needed to be investigated through in vitro and in vivo experiments.

\section{Conclusions}

We identified the IRGs associated with the prognosis of EC and developed an IRGs-based prognostic signature that stratify EC patients into two subgroups with statistically different survival outcomes.

\section{Supplementary Information}

The online version contains supplementary material available at https://doi. org/10.1186/s12885-021-07813-9.

Additional file 1: Supplementary Fig. 1. Analysis of the prognosisrelated IRGs in box plots by Oncomine. A: HSPA6 mRNA expression ( $P$ value:1.10E-10, t-Test:7.750, Fold Change:2.314). B: S100A12 mRNA expression (P-value:0.007, t-Test:2.888, Fold Change:6.630). C: CACYBP mRNA expression (P-value:0.004, t-Test:3.328, Fold Change:1.430). D: NOS2 mRNA expression (P-value:0.010, t-Test:2.485, Fold Change:1.566). E: DKK1 mRNA expression (P-value:0.038, t-Test:1.985, Fold Change:2.128). F: OSM mRNA expression (P-value:3.90E-8, t-Test:5.887, Fold Change: 2.045). G: STC2 mRNA expression (P-value:4.18E-7, t-Test:7.176, Fold Change: 2.293). H: ANGPTL3 mRNA expression (P-value:0.663, t-Test:-0.432, Fold Change:1.169). I: NR2F2 mRNA expression (P-value:0.974, t-Test:-1.972, Fold Change: -1.318).(1: Barrett's Esophagus;2: Esophageal Carcinoma; ${ }^{* *} P<$ $0.001 ;{ }^{* *} P<0.01 ; * P<0.05$; ns: no significance).

Additional file 2: Supplementary Fig. 2. Differences between the immune-related prognostic index and infiltration abundances of other important types of immune cells.

Additional file 3: Supplementary Table 1. Characteristics of the dataset.

\section{Abbreviations}

EC: Esophageal cancer; IRGs: Immune-related genes; TCGA: The Cancer Genome Atlas; TFs: Transcription factors; Tregs: Regulatory T cells; ESCC: Esophagus Squamous Cell Carcinoma; EA: Esophagus 
Adenocarcinoma; ImmPort: Immunology Database and Analysis Portal; DEGs: Differentially expressed genes; FDR: False discovery rate; GO: Gene Ontology; KEGG: Kyoto Encyclopedia of Genes and Genomes; ROC: Receive operating characteristic; AUC: Area under curve; THPA: The Human Protein Atlas; GSEA: Gene Set Enrichment Analysis; BP: Biological Process; CC: Cellular Component; MF: Molecular Function; CTLS: Cytotoxic T lymphocytes; nTregs: Thymus-derived Tregs; iTregs: Inducible Tregs; TPI: Tumor promoting inflammation; FOXO1: Forkhead box protein 01; TK1: Tissue kallikrein

\section{Acknowledgements}

Not Applicable.

\section{Authors' contributions}

JJY conceived this work and ZZ wrote the paper. CC collected and preprocessed the data from TCGA. YF performed the analysis and SL prepared the figures and tables. XHW helped to interpret the results. LS and GRZ revised the manuscript. JJY and GRZ supervised the entire study. All authors have read and approved the manuscript. ZZ and CC contributed equally to this study.

\section{Funding}

This work was supported by Six Talent Peaks Project in Jiangsu Province (CN) [grant numbers: LGY2016025, LGY2016024]; Jiangsu Young Talents Program [grant numbers: QNRC2016655, QNRC2016659]. Jiangsu Institute of Cancer Research Fund (No. ZM201707). Jiangsu Preventive Health Care Foundation (No.Y2018088)

\section{Availability of data and materials}

The datasets analyzed during the current study are available in the TCGA repository (https://portal.gdc.cancer.gov)

\section{Ethics approval and consent to participate}

Not applicable. All data in this study are publicly available and no permission was required to perform this study.

\section{Consent for publication}

Not Applicable.

\section{Competing interests}

The authors declare that they have no competing interests.

\section{Received: 6 August 2020 Accepted: 17 January 2021}

Published online: 04 February 2021

\section{References}

1. Short MW, Burgers KG, Fry VT. Esophageal Cancer. Am Fam Physician. 2017; 95(1):22-8.

2. Simard EP, Ward EM, Siegel R, Jemal A. Cancers with increasing incidence trends in the United States. 1999 through 2008. CA Cancer J Clin. 2012; 62(2):118-28.

3. Huang FL, Yu SJ. Esophageal cancer. Risk factors, genetic association, and treatment. Asian J Surg. 2018:41(3):210-5.

4. Xu L, Li Y, Sun H, Zheng Y, Wang Z, Chen X. Impact of postoperative pathological features of esophageal squamous cell carcinoma on the prognosis. Zhonghua Wei Chang Wai Ke Za Zhi. 2017;20(12):1448-51.

5. Prabhu A, Obi K, Lieberman D, Rubenstein JH. The race-specific incidence of esophageal squamous cell carcinoma in individuals with exposure to tobacco and alcohol. Am J Gastroenterol. 2016;111(12):1718-25.

6. Pennathur A, Gibson MK, Jobe BA, Luketich JD. Oesophageal carcinoma. Lancet. 2013;381(9864):400-12.

7. Bollschweiler E, Plum P, Monig SP, Holscher AH. Current and future treatment options for esophageal cancer in the elderly. Expert Opin Pharmacother. 2017;18(10):1001-10.

8. Cerezo-Wallis D, Soengas MS. Understanding tumor-antigen presentation in the new era of Cancer immunotherapy. Curr Pharm Des. 2016;22(41):623450 .

9. Li B, Cui Y, Diehn M, Li R. Development and validation of an individualized immune prognostic signature in early-stage nonsquamous non-small cell lung Cancer. JAMA Oncol. 2017;3(11):1529-37.

10. Lin P, Guo YN, Shi L, Li XJ, Yang H, He Y, Li Q, Dang YW, Wei KL, Chen G. Development of a prognostic index based on an immunogenomic landscape analysis of papillary thyroid cancer. Aging (Albany NY). 2019;11(2): 480-500.

11. Lee JS. Exploring cancer genomic data from the cancer genome atlas project. BMB Rep. 2016;49(11):607-11.

12. Bhattacharya S, Dunn P, Thomas CG, Smith B, Schaefer H, Chen J, Hu Z, Zalocusky KA, Shankar RD, Shen-Orr SS, et al. ImmPort, toward repurposing of open access immunological assay data for translational and clinical research. Sci Data. 2018;5:180015.

13. Mei S, Meyer CA, Zheng R, Qin Q, Wu Q, Jiang P, Li B, Shi X, Wang B, Fan J, et al. Cistrome Cancer: a web resource for integrative gene regulation modeling in Cancer. Cancer Res. 2017;77(21):e19-22.

14. Ali HR, Chlon L, Pharoah PD, Markowetz F, Caldas C. Patterns of immune infiltration in breast Cancer and their clinical implications. A GeneExpression-Based Retrospective Study. PLoS Med. 2016;13(12):e1002194.

15. Ashburner M, Ball CA, Blake JA, Botstein D, Butler H, Cherry JM, Davis AP, Dolinski K, Dwight SS, Eppig JT, et al. Gene ontology: tool for the unification of biology. The Gene Ontology Consortium. Nat Genet. 2000;25(1):25-9.

16. Kanehisa M, Sato Y, Kawashima M, Furumichi M, Tanabe M. KEGG as a reference resource for gene and protein annotation. Nucleic Acids Res. 2016;44(D1):D457-62.

17. Shannon P, Markiel A, Ozier O, Baliga NS, Wang JT, Ramage D, Amin N, Schwikowski B, Ideker T. Cytoscape: a software environment for integrated models of biomolecular interaction networks. Genome Res. 2003;13(11): 2498-504.

18. Kamarudin AN, Cox T, Kolamunnage-Dona R. Time-dependent ROC curve analysis in medical research: current methods and applications. BMC Med Res Methodol. 2017;17(1):53.

19. Almdahl SM, Jenssen TG, Samdal FA, Burhol PG. The effect of pancreatectomy and gastroenterectomy on the release of somatostatin and vasoactive intestinal polypeptide in experimental fecal peritonitis. Scand J Gastroenterol. 1988;23(1):31-4.

20. Subramanian A, Tamayo P, Mootha VK, Mukherjee S, Ebert BL, Gillette MA, Paulovich A, Pomeroy SL, Golub TR, Lander ES, et al. Gene set enrichment analysis: a knowledge-based approach for interpreting genome-wide expression profiles. Proc Natl Acad Sci U S A. 2005;102(43):15545-50.

21. Vaghjiani RG, Molena D. Surgical management of esophageal cancer. Chin Clin Oncol. 2017;6(5):47.

22. Ku GY. Systemic therapy for esophageal cancer: chemotherapy. Chin Clin Oncol. 2017;6(5):49.

23. Sugie T. Immunotherapy for metastatic breast cancer. Chin Clin Oncol. 2018; 7(3):28.

24. Moy JD, Moskovitz JM, Ferris RL. Biological mechanisms of immune escape and implications for immunotherapy in head and neck squamous cell carcinoma. Eur J Cancer. 2017;76:152-66.

25. Xi M, Liao Z, Deng W, Xu C, Komaki R, Blum M, Hofstetter WL, Ho L, Lin SH. A prognostic scoring model for the utility of induction chemotherapy prior to Neoadjuvant Chemoradiotherapy in esophageal Cancer. J Thorac Oncol. 2017;12(6):1001-10.

26. Winther M, Alsner J, Tramm T, Baeksgaard L, Holtved E, Nordsmark M. Evaluation of miR-21 and miR-375 as prognostic biomarkers in esophageal cancer. Acta Oncol. 2015:54(9):1582-91.

27. Cao HH, Zheng CP, Wang SH, Wu JY, Shen JH, Xu XE, Fu JH, Wu ZY, Li EM, Xu LY. A molecular prognostic model predicts esophageal squamous cell carcinoma prognosis. PLoS One. 2014;9(8):e106007.

28. O'Shea JJ, Holland SM, Staudt LM. JAKs and STATs in immunity, immunodeficiency, and cancer. N Engl J Med. 2013;368(2):161-70.

29. Roshani R, McCarthy F, Hagemann T. Inflammatory cytokines in human pancreatic cancer. Cancer Lett. 2014;345(2):157-63.

30. Agarwal A, Verma S, Burra U, Murthy NS, Mohanty NK, Saxena S. Flow cytometric analysis of Th1 and Th2 cytokines in PBMCs as a parameter of immunological dysfunction in patients of superficial transitional cell carcinoma of bladder. Cancer Immunol Immunother. 2006;55(6):734-43.

31. Kita Y, Mimori K, Iwatsuki M, Yokobori T, leta K, Tanaka F, Ishii H, Okumura $H$, Natsugoe S, Mori M. STC2: a predictive marker for lymph node metastasis in esophageal squamous-cell carcinoma. Ann Surg Oncol. 2011;18(1):261-72.

32. Kashyap MK, Pawar HA, Keerthikumar S, Sharma J, Goel R, Mahmood R, Kumar MV, Kumar KV, Pandey A, Kumar RV, et al. Evaluation of protein expression pattern of stanniocalcin 2, insulin-like growth factor-binding protein 7, inhibin beta a and four and a half LIM domains 1 in esophageal squamous cell carcinoma. Cancer Biomark. 2012:12(1):1-9. 
33. Shinno N, Kimura H, Sada R, Takiguchi S, Mori M, Fumoto K, Doki Y, Kikuchi A. Activation of the Dickkopf1-CKAP4 pathway is associated with poor prognosis of esophageal cancer and anti-CKAP4 antibody may be a new therapeutic drug. Oncogene. 2018;37(26):3471-84.

34. Topolska-Wos AM, Chazin WJ, Filipek A. CacyBP/SIP--Structure and variety of functions. Biochim Biophys Acta. 2016;1860(1 Pt A):79-85.

35. Zhai H, Shi Y, Chen X, Wang J, Lu Y, Zhang F, Liu Z, Lei T, Fan D. CacyBP/SIP promotes the proliferation of colon cancer cells. PLoS One. 2017;12(2): e0169959.

36. Zhai H, Shi Y, Jin H, Li Y, Lu Y, Chen X, Wang J, Ding L, Wang X, Fan D. Expression of calcyclin-binding protein/Siah-1 interacting protein in normal and malignant human tissues: an immunohistochemical survey. J Histochem Cytochem. 2008;56(8):765-72.

37. Zhu L, Miake S, ljichi A, Kawahara S, Kohno M, Sonoyama H, Mitamura Y, Kaku Y, Tsuru H, Tu Y, et al. Upregulated expression of calcyclin-binding protein/siah-1 interacting protein in malignant melanoma. Ann Dermatol. 2014;26(5):670-3.

38. Yang Z, Zhuang L, Szatmary P, Wen L, Sun H, Lu Y, Xu Q, Chen X. Upregulation of heat shock proteins (HSPA12A, HSP90B1, HSPA4, HSPA5 and HSPA6) in tumour tissues is associated with poor outcomes from HBVrelated early-stage hepatocellular carcinoma. Int J Med Sci. 2015;12(3):25663.

39. Ji J, Zhao L, Wang X, Zhou C, Ding F, Su L, Zhang C, Mao X, Wu M, Liu Z. Differential expression of $\$ 100$ gene family in human esophageal squamous cell carcinoma. J Cancer Res Clin Oncol. 2004;130(8):480-6.

40. Wilson KT, Fu S, Ramanujam KS, Meltzer SJ. Increased expression of inducible nitric oxide synthase and cyclooxygenase-2 in Barrett's esophagus and associated adenocarcinomas. Cancer Res. 1998;58(14):2929-34.

41. Brown TJ, Lioubin MN, Marquardt H. Purification and characterization of cytostatic lymphokines produced by activated human T lymphocytes. Synergistic antiproliferative activity of transforming growth factor beta 1, interferon-gamma, and oncostatin $\mathrm{M}$ for human melanoma cells. J Immunol. 1987;139(9):2977-83.

42. Ohata Y, Harada T, Fujii A, Yoshida S, Iwabe T, Terakawa N. Menstrual cyclespecific inhibition of endometrial stromal cell proliferation by oncostatin $\mathrm{M}$. Mol Hum Reprod. 2001;7(7):665-70.

43. Friedrich M, Hoss N, Stogbauer F, Senner V, Paulus W, Ringelstein EB, Halfter $\mathrm{H}$. Complete inhibition of in vivo glioma growth by oncostatin M. J Neurochem. 2001;76(5):1589-92.

44. Kausar T, Sharma R, Hasan MR, Saraya A, Chattopadhyay TK, Gupta SD, Ralhan R. Overexpression of a splice variant of oncostatin M receptor beta in human esophageal squamous carcinoma. Cell Oncol (Dordr). 2011;34(3): $177-87$

45. Zhu L, Jiang L, Wang W, Jia W, Liu F, Jiao X, Zhu X, Bao J, Yu H. Angiopoietin-like protein 3 is an indicator of prognosis in esophageal cancer patients. Int J Clin Exp Med. 2015;8(9):16101-6.

46. Qin J, Wu SP, Creighton CJ, Dai F, Xie X, Cheng CM, Frolov A, Ayala G, Lin X, Feng $\mathrm{XH}$, et al. COUP-TFIl inhibits TGF-beta-induced growth barrier to promote prostate tumorigenesis. Nature. 2013;493(7431):236-40.

47. Nagasaki S, Suzuki T, Miki Y, Akahira J, Shibata H, Ishida T, Ohuchi N, Sasano $\mathrm{H}$. Chicken ovalbumin upstream promoter transcription factor II in human breast carcinoma: possible regulator of lymphangiogenesis via vascular endothelial growth factor-C expression. Cancer Sci. 2009;100(4):639-45.

48. Bringuier PP, Schalken JA, Hervieu V, Giroldi LA. Involvement of orphan nuclear receptor COUP-TFII in cadherin-6 and cadherin-11 regulation: implications in development and cancer. Mech Dev. 2015;136:64-72.

49. Chen Y, Zhang Y, Guo X. Proteasome dysregulation in human cancer: implications for clinical therapies. Cancer Metastasis Rev. 2017;36(4):703-16.

50. Catalgol B. Proteasome and cancer. Prog Mol Biol Transl Sci. 2012;109:27793.

51. Will CL, Luhrmann R. Spliceosome structure and function. Cold Spring Harb Perspect Biol. 2011;3(7):a003707.

52. Effenberger KA, Urabe VK, Jurica MS. Modulating splicing with small molecular inhibitors of the spliceosome. Wiley Interdiscip Rev RNA. 2017; 8(2). https://doi.org/10.1002/wrna.1381.

53. Lee SC, Abdel-Wahab O. Therapeutic targeting of splicing in cancer. Nat Med. 2016;22(9):976-86.

54. Saramago M, da Costa PJ, Viegas SC, Arraiano CM. The implication of mRNA degradation disorders on human DISease: focus on DIS3 and DIS3-like enzymes. Adv Exp Med Biol. 2019;1157:85-98.
55. McGray AJ, Hallett R, Bernard D, Swift SL, Zhu Z, Teoderascu F, Vanseggelen H, Hassell JA, Hurwitz AA, Wan Y, et al. Immunotherapy-induced CD8+ T cells instigate immune suppression in the tumor. Mol Ther. 2014;22(1):20618.

56. Traversari C, Russo V. T cells as antigen carriers for anti-tumor vaccination. Methods Mol Biol. 2016;1393:97-104.

57. Jiang S, Yan W. T-cell immunometabolism against cancer. Cancer Lett. 2016; 382(2):255-8.

58. Mahmoud S, Lee A, Ellis I, Green A. CD8(+) T lymphocytes infiltrating breast cancer: a promising new prognostic marker? Oncoimmunology. 2012;1(3): 364-5.

59. Liu S, Lachapelle J, Leung S, Gao D, Foulkes WD, Nielsen TO. CD8+ lymphocyte infiltration is an independent favorable prognostic indicator in basal-like breast cancer. Breast Cancer Res. 2012;14(2):R48.

60. Pages F, Kirilovsky A, Mlecnik B, Asslaber M, Tosolini M, Bindea G, Lagorce C Wind $P$, Marliot F, Bruneval $P$, et al. In situ cytotoxic and memory T cells predict outcome in patients with early-stage colorectal cancer. J Clin Oncol. 2009;27(35):5944-51

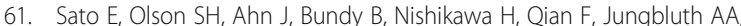
Frosina D, Gnjatic S, Ambrosone C, et al. Intraepithelial CD8+ tumorinfiltrating lymphocytes and a high CD8+/regulatory $T$ cell ratio are associated with favorable prognosis in ovarian cancer. Proc Natl Acad Sci U S A. 2005;102(51):18538-43.

62. Fukunaga A, Miyamoto M, Cho Y, Murakami S, Kawarada Y, Oshikiri T, Kato K, Kurokawa T, Suzuoki M, Nakakubo Y, et al. CD8+ tumor-infiltrating lymphocytes together with CD4+ tumor-infiltrating lymphocytes and dendritic cells improve the prognosis of patients with pancreatic adenocarcinoma. Pancreas. 2004;28(1):e26-31.

63. Kato T, Noma K, Ohara T, Kashima H, Katsura Y, Sato H, Komoto S, Katsube $\mathrm{R}$, Ninomiya T, Tazawa $\mathrm{H}$, et al. Cancer-associated fibroblasts affect Intratumoral CD8(+) and FoxP3(+) T cells via IL6 in the tumor microenvironment. Clin Cancer Res. 2018;24(19):4820-33.

64. Li J, Qiu G, Fang B, Dai X, Cai J. Deficiency of IL-18 aggravates esophageal carcinoma through inhibiting IFN-gamma production by CD8(+) T cells and NK cells. Inflammation. 2018:41(2):667-76.

65. Bilate AM, Lafaille JJ. Induced CD4+Foxp3+ regulatory T cells in immune tolerance. Annu Rev Immunol. 2012;30:733-58.

66. Schmidt A, Oberle N, Krammer PH. Molecular mechanisms of treg-mediated T cell suppression. Front Immunol. 2012;3:51.

67. Gondek DC, Devries V, Nowak EC, Lu LF, Bennett KA, Scott ZA, Noelle RJ. Transplantation survival is maintained by granzyme $B+$ regulatory cells and adaptive regulatory T cells. J Immunol. 2008;181(7):4752-60.

68. Petersen RP, Campa MJ, Sperlazza J, Conlon D, Joshi MB, Harpole DH Jr, Patz EF Jr. Tumor infiltrating Foxp3+ regulatory T-cells are associated with recurrence in pathologic stage I NSCLC patients. Cancer. 2006;107(12):286672.

69. Marshall EA, Ng KW, Kung SH, Conway EM, Martinez VD, Halvorsen EC, Rowbotham DA, Vucic EA, Plumb AW, Becker-Santos DD, et al. Emerging roles of T helper 17 and regulatory $T$ cells in lung cancer progression and metastasis. Mol Cancer. 2016;15(1):67.

70. Frey DM, Droeser RA, Viehl CT, Zlobec I, Lugli A, Zingg U, Oertli D, Kettelhack C, Terracciano L, Tornillo L. High frequency of tumor-infiltrating FOXP3(+) regulatory T cells predicts improved survival in mismatch repairproficient colorectal cancer patients. Int J Cancer. 2010;126(11):2635-43.

71. Badoual C, Hans S, Rodriguez J, Peyrard S, Klein C, Aqueznay Nel H, Mosseri V, Laccourreye O, Bruneval P, Fridman WH, et al. Prognostic value of tumorinfiltrating CD4+ T-cell subpopulations in head and neck cancers. Clin Cancer Res. 2006;12(2):465-72.

72. Droeser R, Zlobec I, Kilic E, Guth U, Heberer M, Spagnoli G, Oertli D, Tapia C. Differential pattern and prognostic significance of CD4+, FOXP3+ and IL$17+$ tumor infiltrating lymphocytes in ductal and lobular breast cancers. BMC Cancer. 2012;12:134.

73. Tzankov A, Meier C, Hirschmann P, Went P, Pileri SA, Dirnhofer S. Correlation of high numbers of intratumoral FOXP3+ regulatory $T$ cells with improved survival in germinal center-like diffuse large B-cell lymphoma, follicular lymphoma and classical Hodgkin's lymphoma. Haematologica. 2008;93(2): 193-200.

74. Wang Y, Lyu Z, Qin Y, Wang X, Sun L, Zhang Y, Gong L, Wu S, Han S, Tang $Y$, et al. FOXO1 promotes tumor progression by increased M2 macrophage infiltration in esophageal squamous cell carcinoma. Theranostics. 2020; 10(25):11535-48. 
75. Chen JY, He LI, Zhang HX, Sun MM, Chen KS. Effects of tumor-associated macrophages on the proliferation and migration of esophageal cancerassociated lymphatic endothelial cells. J Biol Regul Homeost Agents. 2018; 32(2):207-18.

76. Zhou J, Zheng S, Liu T, Liu Q, Chen Y, Tan D, Ma R, Lu X. IL-1 beta from M2 macrophages promotes migration and invasion of ESCC cells enhancing epithelial-mesenchymal transition and activating NF-kappaB signaling pathway. J Cell Biochem. 2018;119(8):7040-52.

77. Dlamini Z, Bhoola KD. Upregulation of tissue kallikrein, kinin B1 receptor, and kinin B2 receptor in mast and giant cells infiltrating oesophageal squamous cell carcinoma. J Clin Pathol. 2005;58(9):915-22.

\section{Publisher's Note}

Springer Nature remains neutral with regard to jurisdictional claims in published maps and institutional affiliations.

Ready to submit your research? Choose BMC and benefit from:

- fast, convenient online submission

- thorough peer review by experienced researchers in your field

- rapid publication on acceptance

- support for research data, including large and complex data types

- gold Open Access which fosters wider collaboration and increased citations

- maximum visibility for your research: over $100 \mathrm{M}$ website views per year

At $\mathrm{BMC}$, research is always in progress.

Learn more biomedcentral.com/submissions 